\title{
The relationship between serum leptin level and disease activity and inflammatory markers in fibromyalgia patients
}

\author{
Safinaz Ataoglu, ${ }^{1}$ Handan Ankarali, ${ }^{2}$ Rumeysa Samanci, ${ }^{1}$ Mustafa Ozsahin, ${ }^{1}$ Ozlem Admis ${ }^{3}$ \\ ${ }^{1}$ Department of Physical Medicine and Rehabilitation, University of Duzce, Medical Faculty, Duzce, Turkey \\ ${ }^{2}$ Department of Biostatistics and Medical Informatics, University of Istanbul Medeniyet, Medical Faculty, Istanbul, Turkey \\ ${ }^{3}$ Department of Biochemistry, University of Duzce, Medical Faculty, Duzce, Turkey
}

\begin{abstract}
OBJECTIVE: The aim of this study was to investigate whether there is a correlation between serum leptin level, disease activity and inflammation markers in patients with fibromyalgia syndrome (FMS).

METHODS: A total of 48 patients with FMS diagnosed according to the 1990 American College of Rheumatology criteria were included in the study, as well as 36 healthy women as controls. The Visual Analogue Scale was used to gauge pain severity, the Fibromyalgia Impact Questionnaire was used to assess physical function, the 36-Item Short Form Health Survey was used to examine quality of life, and depression was measured with the Beck Depression Inventory. Blood samples were examined for erythrocyte sedimentation rate (ESR), C-reactive protein level (CRP), high-sensitivity CRP level (hSCRP), the neutrophil-tolymphocyte ratio (NLR), and the serum leptin level was determined using the enzyme-linked immunosorbent assay method.

RESULTS: The serum leptin level in patients with FMS was significantly higher than in the healthy group. However, no significant relationship was found between leptin level and clinical and inflammatory parameters. In addition, there were no significant differences between the patients and the control group in measurements of ESR, CRP, hsCRP, or NLR.

CONCLUSION: A higher serum leptin level in patients with FMS suggested that leptin may play role in the pathogenesis of FMS, yet there was no relationship between leptin and clinical and inflammatory parameters, suggesting that leptin is not an indicator of disease activity in FMS. Additional research should be performed with larger patient groups.
\end{abstract}

Keywords: Fatigue syndrome; fibromyalgia; inflammation; leptin.

Cite this article as: Ataoglu S., Ankarali H., Samanci R., Ozsahin M., Admis O. The relationship between serum leptin level and disease activity and inflammatory markers in fibromyalgia patients. North Clin Istanb 2018;5(2):102-108.

Cibromyalgia syndrome (FMS), is a complex clinical - entity characterized by widespread body pain and may be associated with numerous symptoms [1]. FMS is a frequently encountered clinical entity, with a prevalence of $2 \%$ to $8 \%$, and an important public health problem, as it causes labor loss, a deterioration in the quality of life of the patient, and significant treatment expenditures [2,3].
Though the etiopathogenesis of FSM is not precisely known, genetic and environmental factors, as well as peripheral and central mechanisms are thought to have roles [4]. Leading hypotheses include central sensitization, central nervous system dysfunction, alterations in neuropeptide levels, neuroendocrinal dysfunction, and sleep disorders, while peripheral hypotheses include

Received: June 06, 2017 Accepted: August 18, 2017 Online: April 16, 2018

Correspondence: Dr. Handan ANKARALI. Department of Biostatistics and Medical Informatics, University of Istanbul Medeniyet, Medical Faculty, Istanbul, Turkey.

Phone: +902162804018 e-mail: handanankarali@gmail.com

(c) Copyright 2018 by Istanbul Provincial Directorate of Health - Available online at www.northclinist.com 
autonomic dysfunction, and structural and functional disorders involving immunological and inflammatory processes, and muscle tissue [5]. The theory that chronic pain in FMS may be the result of inflammation or a response to inflammation has promoted investigation of inflammatory disorders associated with changes in the neuroimmunoendocrine system $[6,7]$. Some of the studies performed thus far have demonstrated increases in the levels of inflammatory markers in FMS $[8,9]$.

Leptin is a multifactorial hormone produced by differentiated adipocytes. It suppresses food intake and increases energy expenditure [10]. Among its many functions in the body, leptin also plays a role in the pathogenesis of inflammation and pain [11]. In the literature, only 4 studies have investigated an association between leptin and FMS. The results of these studies are contradictory, reporting higher, normal, and lower leptin levels [12-14]. The aim of this study was to investigate the correlation between serum leptin level, disease activity, and markers of inflammation, and to compare the leptin level in patients diagnosed with FMS with that of healthy individuals.

\section{MATERIALS AND METHODS}

\section{Sampling and data}

A total of 48 female patients aged between 18 and 60 years who presented at the Düzce University Faculty of Medicine Department of Physical Medicine and Rehabilitation and were diagnosed with FMS based on the 1990 American College of Rheumatology classification criteria, and 36 healthy women were enrolled in the study. All of the participants were informed about the research and provided informed consent forms. Approval was obtained from the ethics committee of Duzce University.

In both groups, a baseline record was made of age, height, weight, body mass index (BMI), educational level, history of surgery, exercise habits, and smoking and alcohol use history. The patients with FMS were asked about the onset of complaints, duration, symptoms of disease, treatments received, and concurrent diseases present, and generalized pain was evaluated. The Visual Analogue Scale (VAS) was used to gauge pain severity, the Fibromyalgia Impact Questionnaire (FIQ) was used to assess disease severity, the 36-Item Short Form Health Survey (SF-36) was used to examine quality of life, and depression was measured with the Beck Depression Inventory (BDI).
Patients with a history of antidepressant use; malignancy; acute or subacute chronic viral/bacterial infection; major psychiatric disease; chronic inflammatory disease; neurological disease; diabetes mellitus or other endocrinological or metabolic disease; age $<18$ or $>60$ years; or current pregnancy or nursing were not included in the study. Furthermore, in order to eliminate the obesity factor on leptin level, women with a BMI $>30 \mathrm{~kg} / \mathrm{m}^{2}$ were excluded.

Following an overnight of fast of 12 hours, venous blood samples were drawn from the patients and healthy controls at between 8:00 and 9:00 am. Three gel vacuum tubes were used for each participant. The first sample was used for routine biochemical analyses (hemogram, erythrocyte sedimentation rate [ESR], rheumatoid factor, thyroid function tests, 25-hydroxy vitamin $\mathrm{D}$, vitamin B12), C-reactive protein (CRP), and high-sensitivity CRP (hsCRP). The second tube was used to measure the serum leptin level, and the third tube was held in reserve as a backup, since hemolysis may affect measurement results.

The blood samples were centrifuged at $3500 \mathrm{rpm}$ for 4 minutes, and the serum was separated. The remainder of the sample was divided into 2 portions, placed in Eppendorf tubes, and kept frozen at $-20^{\circ} \mathrm{C}$ until the day of analysis. The samples were left at room temperature to achieve lysis before the serum leptin level of all of the samples was measured in a single session using the enzyme-linked immunosorbent assay method and a commercial kit (DRG Leptin ELISA Kit; DRG International, Inc., Springfield, NJ, USA). The results were expressed in $\mathrm{ng} / \mathrm{mL}$.

\section{Statistical analysis}

Descriptive statistics of the data were calculated as mean $\pm S D$, numerical values, and percentages, as appropriate, according to the type of data. The fitness of quantitative data to normal distribution was assessed using the Shapiro-Wilk test, and based on the normality of distribution, the groups were compared using an independent samples $t$-test or the Mann-Whitney $U$ test. Correlations between quantitative characteristics were analyzed using the appropriate correlation coefficient. Associations between groups and categorical variables were evaluated using the Pearson chi-square or FisherFreeman-Halton test. PASW Statistics for Windows, Version 18.0 (SPSS, Inc., Chicago, IL, USA) was used to perform the analysis, and the level of statistical significance was accepted as $\mathrm{p}<0.05$. 


\section{RESULTS}

The mean age of the FMS patients and the healthy participants was $38.58 \pm 7.62$ years and $37.86 \pm 9.46$ years, respectively. The mean BMI value of the FMS patients and the controls was $25.02 \pm 3.24 \mathrm{~kg} / \mathrm{m}^{2}$ and $24.44 \pm 2.86$ $\mathrm{kg} / \mathrm{m}^{2}$, respectively. No significant intergroup difference was detected between the mean values for age or BMI $(\mathrm{p}=0.700$ and $\mathrm{p}=0.395$, respectively).

Among the patients, the mean duration of the complaints was $46.93 \pm 61.69$ months (range: 3-360 months), the mean VAS pain score was $6.12 \pm 1.57$ (range: 4-10 points), and the mean number of tender points detected was $14.31 \pm 3.66$ (range: 11-18). Using the cut-off score of 17 points, BDI analysis revealed that $29.2 \%(n=14)$ of the patients were not depressed ( $<17$ points), while $70.9 \%(n=34)$ exhibited depression ( $>17$ points). The mean FIQ score of the FMS patients was $56.23 \pm 18.06$ points.

The educational, professional, and marital status of the patients and the control group is provided in Table 1. There was a larger percentage of housewives among the FSM patients, and statistically significantly fewer manual laborers $(p=0.009)$. Furthermore, a statistically significantly larger number of FMS patients had at most a secondary school education $(p=0.038)$. The distribution of marital status and exercise habit was comparable between the 2 groups ( $p=0.432$ and 0.896 , respectively Table 1). Descriptive values and intergroup comparisons of the subdimensional scores of the SF-36 and the BDI scales are presented in Table 2. The mean values for all of the subdimensional scores of the SF-36 were higher in the control group. However, the mean BDI score and the mean serum leptin level was significantly higher in the FMS group ( $p=0.001$ and $p=0.045$, respectively). There was not a statistically significant difference in the mean serum leptin level between FMS patients with and without depression.

A statistically significant correlation was not found between scale scores, blood parameters, VAS and BMI values, and the serum leptin level in the FMS patients (for each correlation, the coefficient was $<0.20$ and $\mathrm{p}>0.05)$.

Symptoms of FMS observed included fatigue (85.4\%), headache $(85.4 \%)$, restless sleep $(70.8 \%)$, morning stiffness (72.9\%), irritable bowel syndrome (85.4\%), Raynaud syndrome-like symptoms (29.2\%), paresthesia $(83.3 \%)$, sicca syndrome-like symptoms (62.5\%), depression (50\%), anxiety (87.5\%), irritable bladder $(54.2 \%)$, concentration and memory difficulties $(83.3 \%)$,

\section{TABLE 1. Distribution of the professional, educational, and marital status in the patient and control groups}

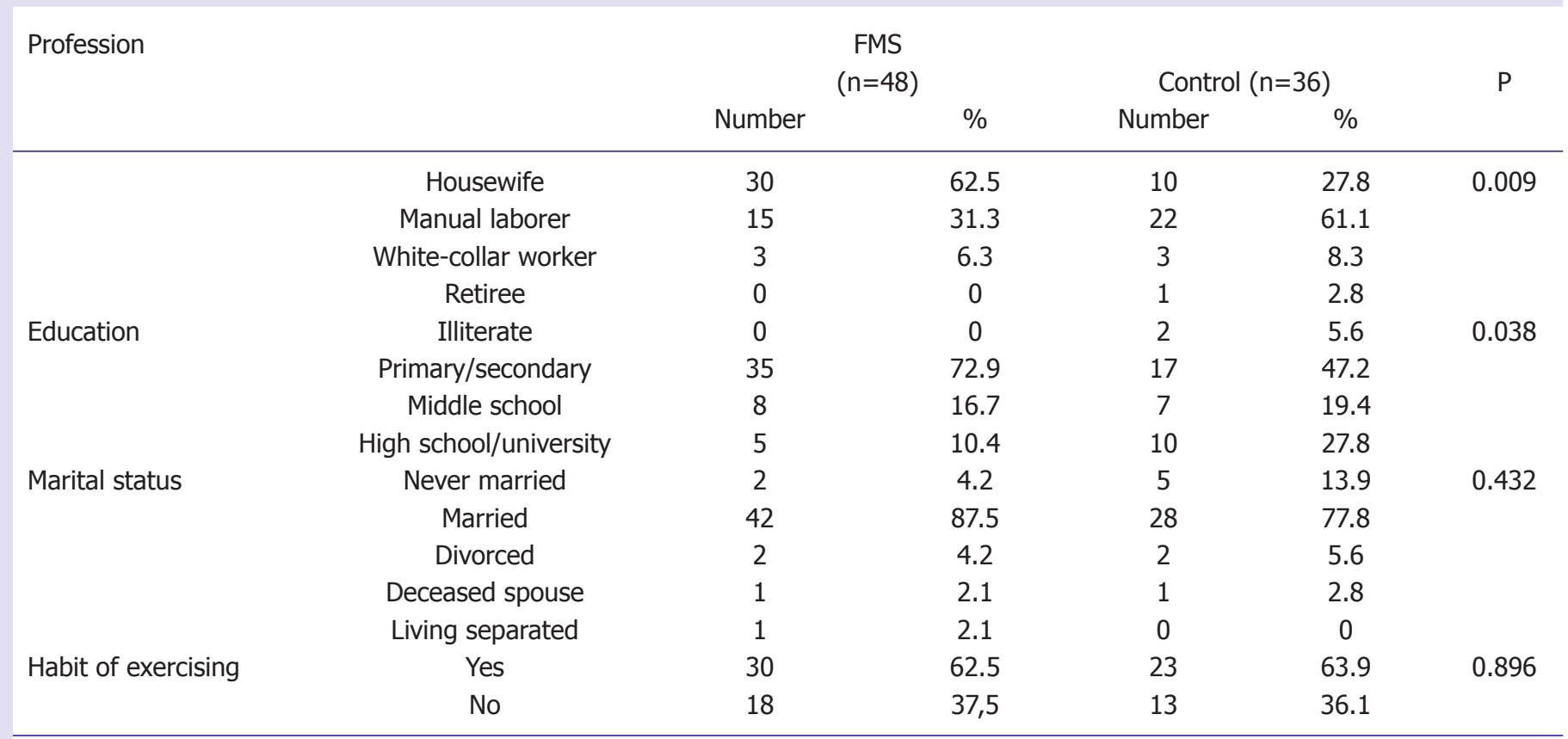

FMS: Fibromyalgia syndrome 
TABLE2. Scale scores and clinical characteristics of the FMS patients and controls

\begin{tabular}{|c|c|c|c|c|c|}
\hline \multirow[t]{2}{*}{ Scale scores and clinical characteristics } & \multicolumn{2}{|c|}{ FMS $(n=48)$} & \multicolumn{2}{|c|}{ Control $(n=36)$} & \multirow[t]{2}{*}{$P$} \\
\hline & Mean & SD & Mean & SD & \\
\hline Physical function & 18.87 & 4.45 & 24.15 & 3.82 & $<0.001$ \\
\hline Physical role difficulty & 5.12 & 1.29 & 6.18 & 1.68 & 0.004 \\
\hline Pain & 5.61 & 1.76 & 8.28 & 1.83 & $<0.001$ \\
\hline General health & 12.72 & 4.05 & 16.44 & 3.70 & $<0.001$ \\
\hline Vitality & 10.58 & 3.53 & 14.39 & 2.80 & $<0.001$ \\
\hline Social function & 6.31 & 1.82 & 7.93 & 1.88 & $<0.001$ \\
\hline Emotional role & 4.16 & 1.20 & 4.75 & 1.27 & 0.046 \\
\hline Mental health & 16.66 & 5.10 & 20.87 & 3.25 & $<0.001$ \\
\hline BDI & 20.14 & 10.52 & 9.36 & 4.52 & $<0.001$ \\
\hline FIQ & 56.23 & 18.06 & --- & --- & --- \\
\hline ESR $(\mathrm{mm} / \mathrm{hr})$ & 14.10 & 11.80 & 15.33 & 10.59 & 0.199 \\
\hline CRP (mg/L) & 0.26 & 0.49 & 0.14 & 0.11 & 0.520 \\
\hline hsCRP (mg/L) & 3.20 & 6.27 & 6.06 & 17.85 & 0.923 \\
\hline NLR & 2.01 & 0.84 & 1.81 & 0.56 & 0.406 \\
\hline Leptin (ng/mL) & 30.32 & 57.25 & 11.15 & 7.06 & 0.045 \\
\hline
\end{tabular}

BDI: Beck Depression Inventory; ESR: Erythrocyte sedimentation rate; FIQ: Fibromyalgia Impact Scale; FMS: Fibromyalgia syndrome; hsCRP: High-sensitivity Creactive protein; NLR: Neutrophil-to-lymphocyte ratio

and dysmenorrhea (43.8\%). The level of leptin did not change significantly in parallel with the presence of FMS symptoms $(p>0.05)$.

\section{DISCUSSION}

The etiopathogenesis of FMS, which is a complex and multidimensional syndrome, is not yet completely known. Therefore, studies continue with the goal of further clarification. Many factors, particularly central sensitization, have been demonstrated to play a part. Although there is strong belief that FMS is not essentially an inflammatory disease, hypotheses that advocate that the chronic pain in FMS is the result of inflammation and/or a response to inflammation are still relevant. 6 In this study, the inflammatory hypothesis was investigated by examining the correlation between FMS disease activity, inflammatory markers, and leptin, which is known to have an effect on pain and inflammation. The serum leptin level of FMS patients was compared with that of healthy individuals.

As a multifunctional hormone, leptin plays a role in both immune system activity and inflammation.1 Studies investigating the relationship between leptin and inflammation have particularly concentrated on chronic inflammatory rheumatic diseases. A growing number of studies are investigating correlations between leptin and rheumatic diseases, such as rheumatoid arthritis, ankylosing spondylitis, systemic sclerosis, and systemic lupus erythematosus, with controversial outcomes [1518]. The role of leptin in inflammation is still not fully understood.

Four studies in the literature have investigated a correlation between leptin and FMS. In these studies, contradictory outcomes were reported, with higher, normal, and lower levels of leptin [12-14, 19].

Fietta and Fietta [19] studied 10 male and 20 postmenopausal women with FMS matched for age, gender, and BMI. They found a significantly higher leptin level in FMS patients when compared with healthy control subjects, and they observed an insignificant decrease in the serum cortisol level. They suggested a potential etiopathogenic role in the interaction between leptin and the hypothalamo pituitary axis (HPA). They also emphasized that leptin may exert negative feedback on the HPA as an adaptation to chronic stress, and psychopathology may become manifest when this mechanism is impaired. Homann et al. 14 investigated a correlation between markers of obesity and the levels of the 2 hormones leptin and ghrelin, which are responsible for energy homeostasis in FMS. They detected a lower ghrelin level, but a higher serum leptin level in FMS patients compared with controls, independent of body fat stores. 
They associated pain with an increase in leptin receptors and sensitivity to leptin, and suggested that there might be a correlation between the clinical state of FMS and an elevated leptin level. Olama et al. [13] found significantly lower leptin levels in 50 female patients with FMS when they were compared with age-, gender-, and BMImatched healthy individuals. They suggested that leptin may be dysregulated in FSM and might have a potential role in the pathogenesis of FMS. In contrast, Ablin et al. [12] did not find a difference in the leptin level between FMS patients and healthy controls. In the present study we found a higher serum leptin level in FSM patients compared with healthy control subjects. Our results were comparable to the results reported by Fietta and Fietta [19] and Homann et al. [14]. The most important disadvantage of the study performed by Homann et al. [14] was the smaller study population. When our results and the other studies are taken into consideration, the elevated leptin level in 3 of 5 studies suggests that a higher leptin level in FSM may suppress the HPA and impair the mechanism so as to adapt to chronic stress with a resultant development of psychopathological disorders. Furthermore, pain may be related to leptin sensitivity. Yet the available results are still insufficient to determine an association between the pathogenesis of FSM and leptin. The most important limitation of this study was its small sample size.

Laposky et al. [20] induced leptin deficiency in rats and found that the deficiency impaired sleep quality and the normal diurnal rhythm of the subjects. In a study of 1024 volunteer participants, Taheri et al. [21] detected a correlation between the level of leptin and reduced duration of sleep. However, most of the studies performed on leptin and sleep disorders were investigating obesity and obesity-related sleep disorders [22]. Piche et al. [23] found that fatigue was associated with an increased leptin level in patients with chronic hepatitis C. Olama et al. [13] observed a lower mean leptin level in FSM patients complaining of post exercise pain, confusion, dizziness, anxiety, short-term memory impairment, mood disorders, temporomandibular joint disorders, palpitations, sleep disorder, and irritable bowel syndrome when compared with FMS patients without these complaints. In the present study, we did not find a correlation between leptin level and fatigue, restless sleep, headache, morning stiffness, or other symptoms.

Olama et al. [13] found a negative correlation between leptin level, the severity of clinical symptoms, functional sufficiency, and quality of life. However, Ablin et al. [12] did not find a correlation between serum leptin level and clinical parameters reflecting the severity of FSM. In this study, too, no significant correlation was found between the serum leptin level of the patients and components of the FIQ and SF-36 scales.

Rats exposed to chronic stress have demonstrated a decreased leptin level, and the administration of leptin reduced depressive behaviors [24]. Yet, in human beings, the meaning of the results of research about leptin is still a question. In various studies, an increased, decreased, or stable level of leptin has been reported in patients with depression [25-27]. It has been suggested that leptin exerts an anxiogenic effect by antigonizing some activities of neuropeptide $Y$, which has anxiolytic properties [28]. Its use has been recommended as a valid neuroendocrinological marker in states of hypervigilance [29]. In this study, no significant difference in leptin level was seen between depressed and nondepressed patients with FMS. Olama et al. [13] also investigated a relationship between depression and serum leptin level, and found a negative correlation between the serum leptin level and BDI score in FMS patients. They reported that leptin may cause negative feedback inhibition in the HPA in order to adapt to chronic stress, and that impairment of this mechanism may result in the development of psychopathological disorders.

In this study, we found a statistically insignificantly higher serum leptin level in FMS patients who had received treatment when compared with untreated FMS patients. Bokarewa et al. [30] also detected a statistically insignificantly higher serum leptin level in treated FMS patients when compared with those who were untreated.

Ablin et al. [12] reported a lack of any significant change in leptin level in FMS after treatment for 3 months. Eser et al. [31] evaluated the effects on leptin level to treatment response to various antidepressants. At least in the short term, they found a marked increase in leptin level with therapeutic response to drug treatment for depression. Various studies have indicated that mirtazapine slightly increased leptin levels, fluoxetine decreased leptin in the short term, and venlafaxine, paroxetine, and tricyclic antidepressants did not change leptin levels [32-34].

Shamsuzzaman et al. [35] investigated the relationship between leptin and CRP, and detected a positive correlation in both men and women. They remarked on the contribution of adipose tissue to the synthesis of both leptin and CRP, which is a source of inflammatory cytokines. However, this strong relationship between leptin and CRP is independent of adipose tissue parameters like BMI and waist-hip ratio, which suggests that 
leptin may increase the CRP level via direct or indirect effects on the immune system. As another possibility, since leptin receptors have similar signal characteristics to interleukin 6 (IL-6) cytokine receptors, it may increase the level of CRP secondary to the induction of cytokines, including IL-6. In this study, we did not observe a significant correlation between the leptin level and inflammatory markers.

Leptin has many functional roles in the body, including an important place in the regulation of pain. Leptin appears to have an important role in the regulation of pain and has been shown to inhibit the response of the HPA axis to stress by inhibiting the secretion of cortisol. 12 Some authors have suggested that leptin-related modulation of pain is realized through a neuropeptide Y-dependent mechanism in the thalamus [36].

Studies performed with patients suffering from chronic pain have detected higher levels of leptin compared with healthy individuals [37]. Some authors have also reported a correlation between leptin and pain in patients with spinal injury, acute coronary syndrome, and osteoarthritis of the knee [38].

Bokarewa et al. [30] investigated the correlation between the levels of leptin and neuropeptide $Y$ and smoking in patients with FMS. They evaluated the impact of smoking on parameters of pain and adipokines in the FMS patients. Smoking was associated with a reduced serum leptin level among FMS patients. Despite a lower leptin level, an expected increase in the neuropeptide $Y$ level was not observed in the smokers. The authors reported that an imbalance between leptin and neuropeptide $\mathrm{Y}$ may be a possible mechanism of the chronic pain seen in FMS. In this study, we thought that a higher leptin level in patients with FMS might be related to the pathophysiology of chronic pain.

Studies investigating the correlation between leptin and BMI have tended to demonstrate the presence of a positive correlation between them [39]. However, our results in this study did not indicate a significant correlation between leptin and BMI.

Our study has some limitations. The most important is that both the patient group and the control group included postmenopausal women. Pamuk et al. [40] reported that postmenopausal FMS patients had described more severe pain, and that the symptoms of some of them started with the onset of menopause or that menopause had exacerbated their symptoms. The level of leptin may be increased by exogenous and endogenous sources that are hard to control, and this may have affected the outcomes of our study. Another limitation is that instead of using detailed anthropometric measurements, we only used BMI values. In addition, the complaints of some of our study participants had started recently, while some of the FMS patients had been experiencing complaints for a long time. Therefore, a more homogenous grouping might prove beneficial.

According to the results of our study, we think that leptin may have a potential role in the etiopathogenesis of FMS. However, our inability to find a correlation between leptin and clinical scores demonstrated that leptin cannot be used as a parameter for the evaluation of disease activity in FMS. We think that larger-scale studies with homogenous patient groups should be conducted to further investigate the correlation between FMS and leptin.

Conflict of Interest: No conflict of interest was declared by the authors.

Financial Disclosure: The authors declared that this study has received no financial support.

Authorship contributions: Concept - S.A., R.S., M.O.; Design S.A., R.S., M.O., H.A.; Supervision - S.A., M.O.; Materials - S.A., M.O., R.S., O.A.; Data collection \&/or processing - H.A., R.S.; Analysis and/or interpretation - H.A., S.A.; Writing - R.S., S.A., H.A.; Critical review - S.A., H.A., R.S., O.A.

\section{REFERENCES}

1. Wolfe F, Clauw DJ, Fitzcharles MA, Goldenberg DL, Katz RS, Mease $\mathrm{P}$, et al. The American College of Rheumatology preliminary diagnostic criteria for fibromyalgia and measurement of symptom severity. Arthritis Care Res (Hoboken) 2010;62:600-10. [CrossRef]

2. Queiroz LP. Worldwide epidemiology of fibromyalgia. Curr Pain Headache Rep 2013;17:356. [CrossRef]

3. Palacio A, Uribe CL, Li H, Hanna J, Deminski M, Alvir J, et al. Financial and clinical characteristics of fibromyalgia: a case-control comparison. Am J Manag Care 2010;16:S118-25.

4. Dadabhoy D, Clauw DJ. Therapy Insight: fibromyalgia-a different type of pain needing a different type of treatment. Nat Clin Pract Rheumatol 2006;2:364-72. [CrossRef]

5. Gür A. Etiopathogenesis in Fibromyalgia. Turk J Phys Med Rehab 2008:54 Suppl 1;4-11.

6. Omoigui $S$. The biochemical origin of pain-proposing a new law of pain: the origin of all pain is inflammation and the inflammatory response. Part 1 of 3-a unifying law of pain. Med Hypotheses 2007;69:70-82.

7. van West D, Maes M. Neuroendocrine and immune aspects of fibromyalgia. BioDrugs 2001;15:521-31. [CrossRef]

8. Toker A, Çiçekler H, Yerlikaya FH, Küçükșen S, Küçük A. Fibromiyalji hastalarında serum sialik asit düzeyleri ve inflamasyon belirteçleri arasındaki korelasyonun araştırılması. Eur J Basic Med Sci 2013;3:24-8.

9. Xiao Y, Haynes WL, Michalek JE, Russell IJ. Elevated serum high-sensitivity C-reactive protein levels in fibromyalgia syndrome patients correlate with body mass index, interleukin- 6 , interleukin-8, erythrocyte sedimentation rate. Rheumatol Int 2013;33:1259-64. [CrossRef]

10. Spitzweg C, Heufelder AE. More clues from fat mice: leptin acts as an opponent of the hypothalamic neuropeptide Y system. Eur J Endocrinol 1997;136:590-1. [CrossRef] 
11. Fantuzzi G, Faggioni R. Leptin in the regulation of immunity, inflammation, and hematopoiesis. J Leukoc Biol 2000;68:437-46.

12. Ablin JN, Aronov N, Shimon I, Kanety H, Pariente C, Aloush V, et al. Evaluation of leptin levels among fibromyalgia patients before and after three months of treatment, in comparison with healthy controls. Pain Res Manag 2012;17:89-92. [CrossRef]

13. Olama SM, Elsaid TO, El-Arman M. Serum leptin in Egyptian patients with fibromyalgia syndrome: relation to disease severity. Int $\mathrm{J}$ Rheum Dis 2013;16:583-9. [CrossRef]

14. Homann D, Carvalho HM, Stefanello JM, Góes SM, Lopes AL, de Oliveira AR, et al. Hyperleptinemia independent of body adiposity in women with fibromyalgia. Rheumatol Int 2014;34:1593-8. [CrossRef]

15. Popa C, Netea MG, Radstake TR, van Riel PL, Barrera P, van der Meer JW. Markers of inflammation are negatively correlated with serum leptin in rheumatoid arthritis. Ann Rheum Dis 2005;64:1195-8. [CrossRef]

16. Toussirot E, Streit G, Nguyen NU, Dumoulin G, Le Huédé G, Saas $\mathrm{P}$, et al. Adipose tissue, serum adipokines, and ghrelin in patients with ankylosing spondylitis. Metabolism 2007;56:1383-9. [CrossRef]

17. Wisłowska M, Rok M, Stepień K, Kuklo-Kowalska A. Serum leptin in systemic lupus erythematosus. Rheumatol Int 2008;28:467-73. [CrossRef]

18. Budulgan M, Dilek B, Dağ ŞB, Batmaz I, Yıldız İ, Sarıyıldız MA, et al. Relationship between serum leptin level and disease activity in patients with systemic sclerosis. Clin Rheumatol 2014;33:335-9. [CrossRef]

19. Fietta P, Fietta P. Counterbalance between leptin and cortisol may be associated with fibromyalgia. Psychiatry Clin Neurosci 2006;60:529.

20. Laposky AD, Shelton J, Bass J, Dugovic C, Perrino N, Turek FW. Altered sleep regulation in leptin-deficient mice. Am J Physiol Regul Integr Comp Physiol 2006;290:R894-903. [CrossRef]

21. Taheri S, Lin L, Austin D, Young T, Mignot E. Short sleep duration is associated with reduced leptin, elevated ghrelin, and increased body mass index. PLoS Med 2004;1:e62. [CrossRef]

22. Ulukavak Ciftci T, Kokturk O, Bukan N, Bilgihan A. Leptin and ghrelin levels in patients with obstructive sleep apnea syndrome. Respiration 2005;72:395-401. [CrossRef]

23. Piche T, Gelsi E, Schneider SM, Hébuterne X, Giudicelli J, Ferrua B, et al. Fatigue is associated with high circulating leptin levels in chronic hepatitis C. Gut 2002;51:434-9. [CrossRef]

24. Kim CS, Huang TY, Garza J, Ramos F, Frazer A, Liu F, et al. Leptin induces antidepressant-like behavioral effects and activates specific signal transduction pathways in the hippocampus and amygdala of mice. Neuropsychopharmacology 2006;31:S237-8.

25. Kraus T, Haack M, Schuld A, Hinze-Selch D, Pollmächer T. Low leptin levels but normal body mass indices in patients with depression or schizophrenia. Neuroendocrinology 2001;73:243-7. [CrossRef]

26. Rubin RT, Rhodes ME, Czambel RK. Sexual diergism of baseline plasma leptin and leptin suppression by arginine vasopressin in major depressives and matched controls. Psychiatry Res 2002;113:255-68.

27. Jow GM, Yang TT, Chen CL. Leptin and cholesterol levels are low in major depressive disorder, but high in schizophrenia. J Affect Disord 2006;90:21-7. [CrossRef]

28. Suomalainen M, Männistö PT. Lack of effect of leptin on the behaviour of mice predicting the level of anxiety and depression. Pharmacol Toxicol 1998;83:139-42. [CrossRef]

29. Liao SC, Lee MB, Lee YJ, Huang TS. Hyperleptinemia in subjects with persistent partial posttraumatic stress disorder after a major earthquake. Psychosom Med 2004;66:23-8. [CrossRef]

30. Bokarewa MI, Erlandsson MC, Bjersing J, Dehlin M, Mannerkorpi K. Smoking is associated with reduced leptin and neuropeptide Y levels and higher pain experience in patients with fibromyalgia. Mediators Inflamm 2014;2014:627041. [CrossRef]

31. Esel E, Ozsoy S, Tutus A, Sofuoglu S, Kartalci S, Bayram F, et al. Effects of antidepressant treatment and of gender on serum leptin levels in patients with major depression. Prog Neuropsychopharmacol Biol Psychiatry 2005;29:565-70. [CrossRef]

32. Kraus T, Haack M, Schuld A, Hinze-Selch D, Koethe D, Pollmächer T. Body weight, the tumor necrosis factor system, and leptin production during treatment with mirtazapine or venlafaxine. Pharmacopsychiatry 2002;35:220-5. [CrossRef]

33. Dryden S, Brown M, King P, Williams G. Decreased plasma leptin levels in lean and obese Zucker rats after treatment with the serotonin reuptake inhibitor fluoxetine. Horm Metab Res 1999;31:363-6. [CrossRef]

34. Hinze-Selch D, Schuld A, Kraus T, Kühn M, Uhr M, Haack M, et al. Effects of antidepressants on weight and on the plasma levels of leptin, TNF-alpha and soluble TNF receptors: A longitudinal study in patients treated with amitriptyline or paroxetine. Neuropsychopharmacology 2000;23:13-9. [CrossRef]

35. Shamsuzzaman AS, Winnicki M, Wolk R, Svatikova A, Phillips BG, Davison DE, et al. Independent association between plasma leptin and C-reactive protein in healthy humans. Circulation 2004;109:2181-5.

36. Elmquist JK, Coppari R, Balthasar N, Ichinose M, Lowell BB. Identifying hypothalamic pathways controlling food intake, body weight, and glucose homeostasis. J Comp Neurol 2005;493:63-71. [CrossRef]

37. Bedaiwy MA, Falcone T, Goldberg JM, Sharma RK, Nelson DR, Agarwal A. Peritoneal fluid leptin is associated with chronic pelvic pain but not infertility in endometriosis patients. Hum Reprod 2006;21:78891. [CrossRef]

38. Karvonen-Gutierrez CA, Harlow SD, Jacobson J, Mancuso P, Jiang Y. The relationship between longitudinal serum leptin measures and measures of magnetic resonance imaging-assessed knee joint damage in a population of mid-life women. Ann Rheum Dis 2014;73:883-9.

39. Tang KL, Wang BL, Yang L, Li LM, Zhou Y, Yang CH. Sexual function improvement in association with serum leptin level elevation in patients with premature ejaculation following sertraline treatment: a preliminary observation. Bosn J Basic Med Sci 2013;13:248-52. [CrossRef]

40. Pamuk ON, Cakir N. The variation in chronic widespread pain and other symptoms in fibromyalgia patients. The effects of menses and menopause. Clin Exp Rheumatol 2005;23:778-82. 